mixtures of acids and other substances with water frequently show very pronounced maxima. A single maximum was found by Graham in sulphuric acid $\left(20^{\circ}\right)$ near to the composition $\mathrm{H}_{3} \mathrm{SO}_{4}, \mathrm{H}_{2} \mathrm{O}$. The relative viscosities of solutions of phosphoric acid of concentrations from 90.6 and 98 . I per cent. were determined at $25^{\circ} \pm 0.0$ with an Ostwald viscosimeter. The measurements were not made with the same accuracy as were those of the conductivity, and the data are therefore omitted here. It is sufficient to say that, when time of outflow was plotted against concentration, the very slight irregularities in the curve were within the experimental error, and no marked flexure occurs within the range of concentrations examined.

\title{
THE SIZE OF THE PORES IN PORCELAIN AND OSMOTIC EFFECTS.
}

BY S. I, AWRENCE BIGELOW AND F. E. BARTEIL.

Received Septeitubet 6 , rgog.

Several methods have been tried in this laboratory to obtain experimental facts bearing upon the question whether or not a membrane, with which osmotic phenomena may be obtained, is or is not a network of capillaries. This article contains the results secured by one of these methods.

In a previous article by one of $1 s^{1}$ it was shown that water passes through collodion, goldbeater's skin, parchment paper and unglazed porcelain membranes at rates conforming to the known formulations for the flow of water through capillary tubes. This was considered as strong, though not conclusive, evidence that these membranes consist of networks of capillaries. It was not possible to estimate the probable diameters of these capillaries, for Poisetille's formula contains, as one term, the length of the tube. The capillaries in these membranes cannot be considered as perpendicular to the surfaces and so the thickness of the membrane cannot be taken as their length. But Jurin's law furnishes a method for calculating the diameters of such tubes which is independent of their lengths. $a^{2}=h r$, where $r$ is the radius of the tube, $h$ is the height to which the liquid ascends due to capillarity, and $a^{2}$ is one of the so-called capillary constants. For water at $19^{\circ}, a^{2}=14.846 \mathrm{~mm}$. We may then calculate the radius of a tube if we know the height to which water ascends in it, from the formula, $h r=14.846 \mathrm{~mm}$. Furthermore, if water fills a short length of capillary, it will require the hydrostatic pressure of a column of water equal to the height to which water would ascend in such a capillary, to force it out. By measuring the pressure required to force the water out of a membrane saturated with water we can then estimate the radius or diameter of the pores in that membrane.

\footnotetext{
1 'THIS JoUrnal, 29, 1675 (1907).
} 
This method has been used recently by Bechhold ${ }^{1}$ in his work on ultra filtration, and a similar method was used by Barus. ${ }^{2}$ We have not thus far found in the literature that a comparison between the pore sizes thus measured and the osmotic effects of membranes was ever instituted.

Apparatus and Method.-Our membranes were different grades of unglazed porcelain and we determined the pressures required to force water out of them in an apparatus as shown in Fig. I.

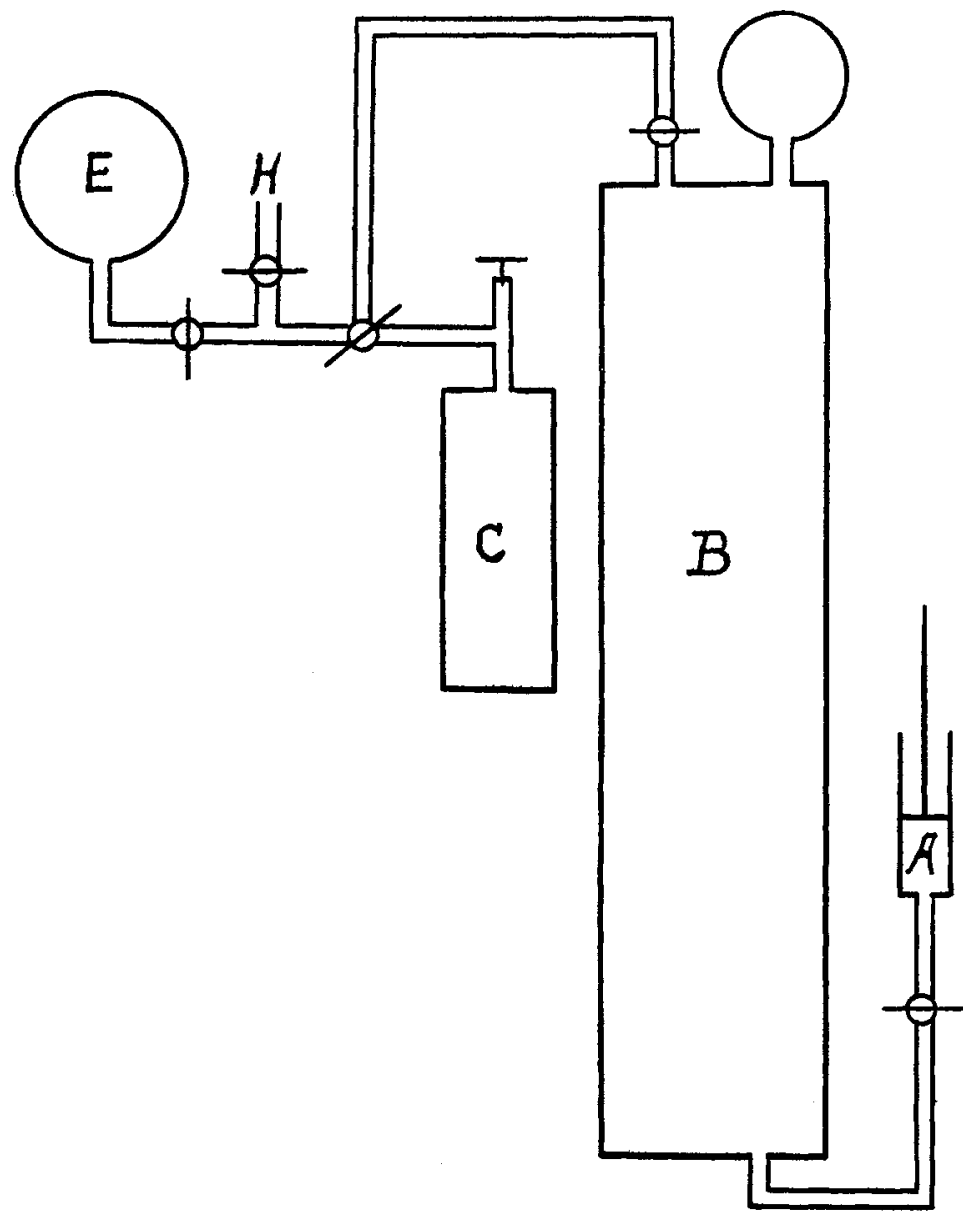

Fig. I.

By means of the force pump $A$, water was pumped into tank $B$ (I Io $\mathrm{cm}$. high by $\mathrm{I} 6 \mathrm{~cm}$. diameter). The air thus compressed was transferred to the smaller tank $C(29 \mathrm{~cm}$. high by $8 \mathrm{~cm}$. diameter $)$. The experimental

${ }^{1} Z$. physik. Chem., 64, 328 (1908).

'Am.J.Sci., 48, $45^{2}$ (1894). 
cell was attached at $H$, and $E$ represents the pressure gauge by which the pressures given in the tables were found.

It is not easy to make tight joints between unglazed porcelain plates, glass and brass tubing. We accomplished this, however, with washers of dermatine, the naterial used for a similar purpose by the Earl of Berke-

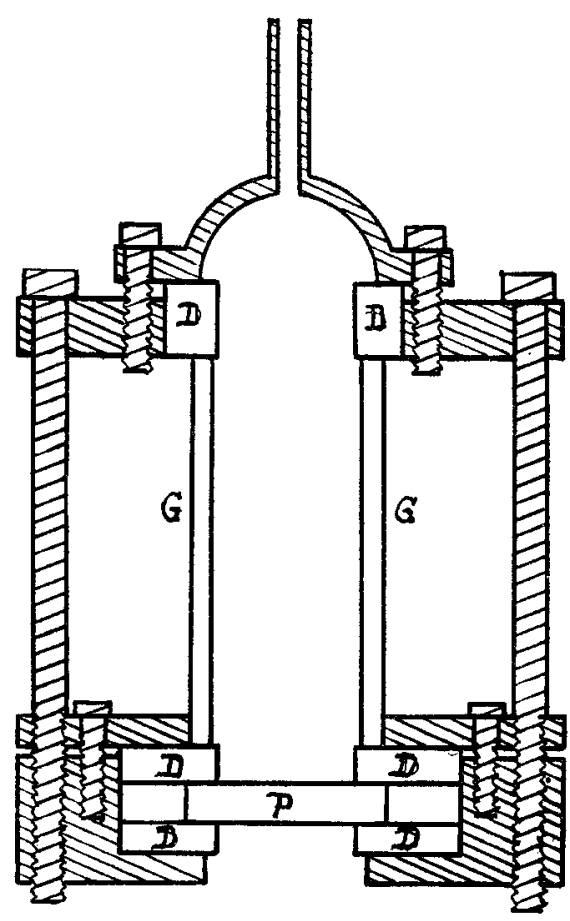

Fig. 2. ley and Hartley. ${ }^{1}$ Figure 2 gives a detailed plan of our cell, drawn to scale, actual size.

The essential parts are the porcelitin plate $I^{\prime}$, about $20 \mathrm{~mm}$. in diameter, held between the two dermatine washers $D, D$, which left exposed a surface $14 \mathrm{~mm}$. in diameter. The porcelain plates were generally $4 \mathrm{~mm}$. in thickness, but some as thin as $2 \mathrm{~mm}$. and others as thick as $5 \mathrm{~mm}$. were used. The thickness between these limits had no effect on our results. The stout glass cylinder $G, 40 \mathrm{~mm}$. long, I5 mm. internal diameter, with ground ends, was also held between dermatine washers. The rest of the cell was of brass, put together with screws by which much pressure could be brought to bear.

In carrying out an experiment the porcelain dise was first saturated by forcing water through it.

All water not in the pores was then removed and the cell was attached to the pressure apparatus with the dise facing upwards, and slowly increasing air pressure was applied. A piece of heary plate glass was held just above, for these discs frequently burst, and through this we watched carefully, with a lens, for the appearance of air bubbles on the upper surface. We noted the pressure at which the first bubble appeared, but we took as the pressure from which to calculate the pore diameter that at which between 100 and 200 bubbles could be counted.

After the pressure required to displace the water with air had been determined, the cell was disconnected from the pressure apparatus, filled with normal sugar solution, provided with a glass tube, $3 \mathrm{~mm}$. internal diameter, and placed, porcelain disc downwards, in a beaker of distilled water. In other words, without disarranging disc or glass cylinder,

'Phil. Trans., Series A, 206, 48I (1906). 
the apparatus was converted into an "osmotic cell" experiment. The meniscus of the sugar solution within was adjusted at $8 \mathrm{~mm}$. above the level of the distilled water without. If this meniscus rose we considered the membrane as capable of showing osmotic effects. We waited as a rule 24 hours, sometimes 48 or more hours, before drawing our conclusion.

It should be clearly understood that we made not the slightest effort to determine any maximum or quantitative osmotic pressures. Our attention was directed exclusively to the qualitative side. Any other course would have been absurd with these membranes, for they all contained pores of large and of small diameters, and in most instances there could not have been much difference between the endosmotic and the exosmotic currents.

In both the pressure determinations and osmotic tests we held the temperature close to $19^{\circ}$ and did not allow it to vary more than one degree either way. In future, more careful work we shall pay stricter attention to our temperatures.

We measured our pressures, $P$, in kilograms per square centimeter; therefore, substituting in Jurin's formulation, $\frac{I 4.846 \times 2}{\mathrm{I} 0000 \times \mathrm{P}}$ gives us the diameter of the pores in millimeters.

Preliminary Test of Apparatus and Method.-Our calculations gave us diameters just ten times those calculated by Bechhold from the same pressures, and being unable to find an error in our reasoning, we subjected our method to the following direct experimental test. We drew out fine glass capillaries, filled them with water and determined the mercury pressure required to force out this water with air. These experiments also were carried out at $19^{\circ}$. To convert mercury pressure to water pressure we multiplied the former by 13.56 , and this result we multiplied by two to obtain the diameter. Our formula then was, $14.846 \times 2 / 13.56 \times \mathrm{mm} . \mathrm{Hg} .=\mathrm{D}$, diameter in mm. Having determined the pressure and calculated the diameter, we measured the diameter of the tube directly under a microscope. Table I shows some of our results. The first column contains the pressures in mm. of mercury, the second the diameters in mm. as calculated from these pressures, the third the diameters actually measured under the microscope.

\section{TABLE I.}

$\begin{array}{rcc}\text { P. } & \text { D, calculated. } & \text { D, observed. } \\ 22 & 0.099 & 0.114 \\ 33 & 0.066 & 0.064 \\ 48 & 0.046 & 0.047 \\ 65 & 0.034 & 0.033 \\ 25^{8} & 0.0085 & 0.008\end{array}$


We are inclined to attribute the divergence between Bechloid's figures and ours to a misprint, a misplaced decimal, in his article, becanse of the above satisfactory direct experimental verification of our calculations.

Experiments.-Cable II contains sone of our results with different samples of porcelain. Pressures, $P$, are given in kilograms per square centimeter and diameters of pores, $D$, are given in microns. In all of the following tables each result is the average of at least three independent determinations.

\begin{tabular}{rll} 
P. & \multicolumn{1}{c}{ TARLE II. } & \\
2.5 & D. & Osmotic effect. \\
2.6 & 1.18 & None. \\
4.5 & 1.14 & None. \\
5.0 & 0.65 & None. \\
6.0 & 0.59 & None. \\
7.0 & 0.49 & None. \\
8.0 & 0.42 & Possibly a slight effect. \\
8.5 & 0.37 & Surely some effect. \\
15.0 & 0.34 & More effect.
\end{tabular}

This table shows that if the diameter of the pores is more than the 7 kilo value there is no osmotic effect, while if it is less than this there is osmotic effect. This is evidence in faror of the view that the osmotic effect is intimately connected with the size of the pores, and this evidence is further strengthened by the fact that the smaller the pores the more marked the osmotic effects.

We next took porcelain of such coarse srain that no osmotic effects could be obtained with it and clogged its pores by precipitating bariun sulphate within it. The porcelain was first saturated with an $\mathrm{m} / 2^{1}$ barium chloride solution, then immersed in sodium sulphate solutions of different concentrations. Table III contains some of our results with these modified membranes. TABLE III.

$\begin{array}{rcc}\text { P. } & \text { D. } & \text { Osmotic effect. } \\ 3 & 0.98 & \text { None. } \\ 4 & 0.74 & \text { Slight effect. } \\ 5 & 0.59 & \text { Marked effect. } \\ 6 & 0.49 & \text { Marked effect. } \\ \text { I2 } & 0.24 & \text { Marked effect. }\end{array}$

It is evident that by so clogging the pores of porcelain we can make it act "osmotically" and this is additional evidence in favor of the view that osmotic effects are intimately connected with the size of the pores.

We next clogged the pores of porcelain, which by itself gave no osmotic effects, with finely divided sulphur, precipitating it from sodium thiosulphate solutions with dilute sulphuric acid. Table IV contains some of our results with these membranes:

1 Molecular normal. 
TABLE IV.

$\begin{array}{rcl}\text { P. } & \text { D. } & \text { Osmotic effect. } \\ 3.2 & 0.93 & \text { None. } \\ 4.0 & 0.74 & \text { None. } \\ 4.5 & 0.66 & \text { None. } \\ 5.0 & 0.59 & \text { Possibly a slight effect. } \\ 6.0 & 0.49 & \text { Surely some effect. } \\ 8.0 & 0.37 & \text { Marked effect. } \\ 12.0 & 0.25 & \text { Marked effect. } \\ 14.0 & 0.21 & \text { Marked effect. } \\ 18.0 & 0.16 & \text { Marked effect. }\end{array}$

Here again we find the same evident intimate connection between pore diameters and osmotic effects.

\section{Summary and Conclusions.}

The maximum pore diameter for a distinct osmotic effect with porcelain is 0.37 micron, with porcelain clogged with barium sulphate is 0.59 micron, with porcelain clogged with sulphur is 0.49 micron. It is evident enough, from the description of the method above, that these are nothing but approximations, yet it is interesting that they are so much larger than the probable molecular dimensions.

These values are at least of the same order of magnitude and the agreement is probably as close as we could expect, for large errors are possible in determining the pressure at which between Ioo and 200 bubbles may be counted. Since they are not the same, we cannot assert that the nature of the material makes no difference, but they are so nearly the same it would seem that the diameter of the capillary is the main factor in determining the appearance of osmotic phenomena.

Certainly it would not be easy to harmonize these results with the theory that the membrane in osmotic experiments acts as a solvent, as this theory is ordinarily stated by recent writers. But osmotic effects can be obtained where the membrane without question dissolves the substance passing through, as was first shown by Lhermite, ${ }^{1}$ the originator of the solution theory, with his three-liquid-layer experiments. As was said in the article by one of us already cited, the most logical view is contained in the suggestion made by Lhermite, that the mechanism of the process of solution itself is probably capillary in its nature.

We have other experiments under way and many more in mind, but we have no desire to reserve the field. On the contrary, we should welcome additional and independent determinations.

University of Michigan, ANx ARBor.

${ }^{1}$ Ann. chim. phys. [3], 43, 420 (1855). 